\title{
The Supreme Court Decision on Obama Care Part III: The Unintended Consequences on the Already Insured
}

\author{
Gilbert Berdine, MD
}

Part I of this series discussed the direct legal consequences of the Supreme Court Decision on the Affordable Care Act (ACA). Part II predicted that proposed cost savings would not, in fact, be realized by the expansion of insurance coverage. Part III discusses the unintended consequences of ACA on those people who are already insured and are content with their coverage.

ACA will lead to substantial unintended effects on those who already have insurance paid for by their employer. Many companies offer health benefits to some full time employees. ACA will increase the cost of the policies and require that a greater number of employees be covered. Some employers will drop health insurance as a paid benefit.

The owner of a group of KFC franchises illustrated the effects of ACA on his insurance costs. ${ }^{1}$

Barr has 23 stores with 421 employees, 109 of whom are full-time. Of those, he provides 30 with health insurance. Barr said he pays 81 percent of their Blue Cross Blue Shield policy, or $\$ 4,073$ of $\$ 5,028$ for individuals, more for families, for a total bill of $\$ 129,000$ a year. Employees pay $\$ 995$.

Under Obamacare, however, he will have to provide health insurance for all 109 full-time workers, a cost of $\$ 444,000$, or two and half times more than his current costs. That $\$ 315,000$ increase is equal to just over half his annual profit, after expenses, or 1.5 percent of sales. As a result, he said, "I'm not paying $\$ 444,000$."

Providing no insurance would result in a federal

Corresponding author: Gilbert Berdine MD Contact Information: Gilbert.Berdine@ttuhsc.edu DOI: $10.12746 /$ swrccc 2013. 0103.029 fine of $\$ 158,000, \$ 29,000$ more than he now spends but the lowest cost possible under the Obamacare law. So he now views that as his cap and he'll either cut worker hours or replace them with machines to get his costs down or dump them on the public health exchange and pay the fine. "Every business has a way to eliminate jobs," he said, "but that's not good for them or me."

Note the businessman assumed that the premiums for his employees would not go up. He is mistaken about that assumption, so the actual figure would be higher than $\$ 444,000$. The businessman currently pays a lower premium than the average health care cost due to the actuarial expectation that his working employees are healthier than the unemployed. Since ACA eliminated risk stratification on the basis of pre-existing conditions, the average premium must rise to the average per capita cost of health care. As analyzed in Part II of this series, the premium of $\$ 5,028$ would increase to greater than $\$ 7,535$. $^{2}$

ACA includes subsidies for premiums to entice low income participants. The magnitude of the effect of these subsidies is unknown, but all subsidies increase the price of a product. The Society of Actuaries has predicted significant increases that vary greatly from state to state. ${ }^{3}$ Their predictions for Wisconsin were made in great detail.

Note that the stratification of risk (and premium) for age is retained by ACA. The premiums for all age groups are expected to rise. This study has been criticized by the Congressional Budget Office (CBO), which has predicted premium increases by only 10$13 \%$, but the CBO does not include subsidies in its figures for premiums. The subsidies must be paid by someone and must be included in the total cost of health care.

The implementation of ACA will have adverse effects on employment. Some businesses will lay off 
workers to get under the minimum number of employees that ACA requires. Some businesses will reduce working hours to convert full time employees to part time employees. HHS and IRS needed 18 pages to "explain" the definition of a full time employee. ${ }^{4} \mathrm{~A}$ full time employee has been redefined as one who works 30 hours per week. Some businesses will look for ma- chinery to replace employees. No employer will voluntarily increase employment in order to voluntarily pay the higher insurance costs. The individual mandate is a coercive regulation that people will try to circumvent. The CBO has concluded that seven million workers will lose employer provided insurance due to ACA $^{5}$

\begin{tabular}{|c|c|c|c|c|}
\hline Age & $\begin{array}{c}\text { Number Newly } \\
\text { Insured Under } \\
\text { ACA }\end{array}$ & $\begin{array}{c}\text { Average } \\
\text { Monthly Cost } \\
\text { Pre-ACA }\end{array}$ & $\begin{array}{c}\text { Average } \\
\text { Monthly Cost } \\
\text { Post-ACA }\end{array}$ & $\begin{array}{c}\text { Percent } \\
\text { Change in } \\
\text { Average Costs }\end{array}$ \\
\hline Under 19 & 30,848 & $\$ 101$ & $\$ 183$ & $80.6 \%$ \\
\hline $19-24$ & 94,229 & $\$ 100$ & $\$ 199$ & $97.8 \%$ \\
\hline $25-34$ & 77,325 & $\$ 146$ & $\$ 236$ & $61.8 \%$ \\
\hline $35-44$ & 57,813 & $\$ 226$ & $\$ 400$ & $76.5 \%$ \\
\hline $45-54$ & 51,056 & $\$ 221$ & $\$ 786$ & $254.9 \%$ \\
\hline 55 \& over & 47,612 & $\$ 380$ & $\$ 730$ & $92.1 \%$ \\
\hline
\end{tabular}

ACA will insure the poor via an expansion of Medicaid. Participating in Medicaid does not imply access to office visits. Some states, including Texas and Florida, have announced they will not participate in the ACA expansion of Medicaid. There are many doctors who will not see new Medicaid patients, so even if one lives in a state that does expand Medicaid, there is no guarantee one will have access to a doctor's office.

ACA does not expand the number of doctors, the number of nurses, or the number of office visit slots. New Medicaid patients can only be accommodated by increasing the workloads of health care workers or by delaying the care of existing insured patients. Increasing workloads will necessarily increase costs unless reimbursements are decreased. Part of ACA is a planned decrease in Medicare reimbursement. At some point, reimbursement falls below the cost of providing the service and that service will no longer be available to Medicare patients. To the extent that doctors keep workload and costs constant, new Medicaid patients will delay care for the existing insured patients.

Nobody can be certain what the exact effects of ACA will be on national health care costs or quality. We do know for certain, however, that all subsidies increase utilization, total cost, and price per transaction. ACA creates subsidies for those with pre-existing conditions and new subsidies for low income participants.

While we do not know, exactly, how society will respond to ACA, we have some data from the experience of RomneyCare in Massachusetts, and that data support predictions based on Austrian economics. A report on RomneyCare written by the Cato Institute notes: "According to insurance industry insiders, the plans are too costly for the target market, and the potential customers- largely younger, healthy men-have resisted buying them. Those who have signed up 
have been disproportionately older and less healthy. This should come as no surprise since Massachusetts maintains a modified form of community rating, which forces younger and healthier individuals to pay higher premiums in order to subsidize premiums for the old and sick." 6 The RomneyCare mandate was successful at providing insurance for those who were completely or heavily subsidized. A majority of people who do not qualify for premium subsidies, however, refused to participate. Rather than shrinking health care costs, RomneyCare is already significantly over budget. A recent review of RomneyCare by the Wall Street Journal reached similar conclusions.

"Sure enough, $79 \%$ of the newly insured are on public programs. Health costs-Medicaid, RomneyCare's subsidies, public-employee compensation - will consume some $54 \%$ of the state budget in 2012, up from about $24 \%$ in 2001. Over the same period state health spending in real terms has jumped by $59 \%$, while education has fallen $15 \%$, police and firemen by $11 \%$ and roads and bridges by $23 \%$.

Meanwhile, Massachusetts spends more per capita on health care than any other state and therefore more than anywhere else in the industrialized world. Costs are $27 \%$ higher than the U.S. average, $15 \%$ higher when adjusted for the state's higher wages and its concentration of academic medical centers and specialists." 7

The Wall Street Journal article commented next on the price controls and authoritarian regulations employed to curb costs. Similar controls are being implemented by the federal health care bureaucracy either as part of ACA or in parallel with it. October 1, 2010, marked the dawn of a new program that exacts penalties from hospitals that readmit patients too soon. The Associate Press notes:

"About two-thirds of the hospitals serving Medicare patients, or some 2,200 facilities, will be hit with penalties averaging around $\$ 125,000$ per facility this coming year, according to government estimates." 8

The penalties are not attempts to reign in outlier behavior. These penalties are simply a disguise for decreased reimbursements. Nor will the penalties likely have the intended effect. Providers will find ways to circumvent the penalties such as admitting more and more patients who could be easily treated at home in order to pad their statistics. The only way these government programs will reduce health care costs is to make services unavailable to anyone at any price.

The stated goals of ACA are to increase the number of people covered by insurance and to decrease the cost of health care. Simple economic analysis demonstrates that these goals are mutually exclusive. Socialization of costs always leads to increased utilization of services and runaway aggregate costs. The only ways to decrease health care costs are to increase supply and reduce demand. ACA makes no effort to increase supply and intends to change demand in the wrong direction. Convoluted schemes that supposedly pay for themselves never seem to realize the promised benefits. RomneyCare has demonstrated failures that are certain to follow in the wake of the Supreme Court decision on ACA.

Author Affiliation: Dr. Berdine is a pulmonary physician in the Department of Internal Medicine, TTUHSC.

Received: $11 / 20 / 2012$

Accepted: 5/29/2013

Reviewers: Clarke Cochran PhD, Kenneth Nugent MD

Published electronically: 7/16/2013

Conflict of Interest Disclosures: None

\section{References}

1. http://washingtonexaminer.com/franchisors-warn-obamacare-will-halve-profits/article/2507920\#.UG2DLq4uN6a

2.http://pulmonarychronicles.com/ojs/index.php?journal= pulmonarychronicles\&page $=$ article \&op $=$ view\&path[] $=62$ \&path[] $=134$

3. http://cdn-files.soa.org/web/research-cost-aca-report.pdf 4. http://washingtonexaminer.com/feds-need-18-pages-todefine-full-time-for-obamacare/article/2507528\#.UG2DdK4uN6Y

5. http://www.cbo.gov/publication/44008

6. http://www.cato.org/pubs/policy_report/v30n1/cpr30n1 $-1 . h$ tml

7. http://online.wsj.com/article/SB1000087239639044368

7504577563000563259044.html

8. http://hosted.ap.org/dynamic/stories/U/US_MEDI-

CARE PENALTIES?SITE $=$ AP\&SECTION $=\bar{H}$ OME $\&-$ TEMPLATE $=$ DEFAULT\&CTIME=2012-09-30-05-02-01 